Gut, 1984, 25, 393-397

\title{
Endoscopic examination of the gastric remnant 31-39 years after subtotal gastrectomy for peptic ulcer
}

\author{
I R PICKFORD, J L CRAVEN, R HALL, \\ G THOMAS, AND W D STONE \\ From the York Peptic Ulcer Trust, York District Hospital, York
}

SUMmARY In York between 1941 and 1949, 632 patients underwent Polya partial gastrectomy for peptic ulcer. Of 307 patients who were followed up in the York Gastric Clinic from 1971 to 1980, nine died of gastric cancer, three times the expected number. If gastrectomy was performed for gastric ulcer the risk of later development of carcinoma (7\%) was significantly greater than that following operation for duodenal ulcer $(1.6 \%)(\mathrm{p}<0.001)$. No cancers were diagnosed in the 54 patients endoscoped. Atrophic gastritis was found in $98 \%$ of patients and intestinal metaplasia in $44 \%$. Dysplasia was present in $35 \%$ but in no case was it severe. Although we have found that there is an increased risk of cancer developing in the gastric remnant we do not consider routine endoscopic follow up of all postgastrectomy patients to be a practical proposition.

Carcinoma developing in the gastric remnant after partial gastrectomy for peptic ulcer has been reported on many occasions, as a result of which it has been suggested that the gastric remnant is subject to a greater risk of malignant change than the intact stomach. ${ }^{1-8}$

Most of these 'gastric stump' carcinomas become clinically evident during the third postoperative decade, and are almost invariably advanced when diagnosed. In several studies reported recently an attempt has been made to detect the cancers at an earlier stage by endoscopic examination of asymptomatic patients, 15 years or more after operation. ${ }^{9-13}$ These studies have revealed a significant number of clinically unsuspected carcinomas and a high incidence of mucosal abnormalities including atrophic gastritis, dysplasia, and intestinal metaplasia. It has been recommended, therefore, that all postgastrectomy patients require routine endoscopic follow up. ${ }^{9} 1013$

This study was undertaken to evaluate the feasibility and practicality of gastroscopy in the long term management of postgastrectomy patients, particularly with respect to making an earlier diagnosis of carcinoma arising in the 'gastric stump', and to determine their risk of gastric cancer.

Address for correspondence: Mr I R Pickford, FRCS, Scarborough Hospital. Scarborough, N Yorks.

Accepted for publication 21 June 1983

\section{Methods}

PATIENTS

In York between 1941 and 1949 one surgeon (the late Mr Hedley Visick) performed 632 Polya partial gastrectomies for peptic ulcer. All the resections were two thirds or greater and almost half were 'measured radical gastrectomies' in which he left a remnant measuring one and a half inches on the lesser curve and three inches on the greater curvature. ${ }^{14}$

Four hundred and ninety nine operations were performed for duodenal ulcer, 94 for gastric ulcer, and 39 for combined gastric and duodenal ulcer disease.

This study is principally concerned with 307 (267 men, 40 women) patients who were alive in 1971 and have been followed up since in the York Gastric Clinic. All patients attending follow up in 1980 were offered gastroscopy after its possible relevance had been explained. Before gastroscopy the patients were asked of symptoms suggestive of gastric malignancy and were examined. An Olympus GIFP gastroscope was used throughout and multiple biopsies (six to eight) were taken from the peristomal gastric mucosa and from any suspicious looking lesions.

Specimens were fixed in $10 \%$ formol saline, processed routinely into paraffin and sectioned at 5 $\mu \mathrm{m}$. Specimens from the anterior and posterior 
walls were stained with haematoxylin and eosin, alcian blue, and by the PAS technique without diastase digestion. All the sections were reviewed by one pathologist (GT) without knowledge of the clinical or endoscopic findings or of reports issued previously. The presence of gastritis was classified according to the criteria of Whitehead ${ }^{15}$ and graded 0-3. Epithelial dysplasia, when present, was graded as described by Savage and Jones. ${ }^{11}$ Dysplastic changes were recorded only when the activity of gastritis was absent or minimal.

Histological examination of the gastric remnant was possible in nine of the patients who developed cancer, and the tumours classified according to the criteria of Lauren. ${ }^{16}$

The risk of gastric cancer in the postgastrectomy patients was estimated as follows: the number of deaths from gastric carcinomas in the 307 patients followed up in York (observed deaths) between 1971-80 was compared with the expected number of deaths from cancer of the stomach in the patients over the same 10 year period. From their ages at the start it was possible to calculate the "person years at risk' for each five year age group to the end of the follow up period in 1980. The expected number of deaths from gastric cancer was then calculated by multiplying the 'person years at risk' by the appropriate age specific mortality rates for cancer of the stomach. The average age specific mortality rates for England and Wales for carcinoma of the stomach for 1971 to 1979 were used (Table 1).

The differences in the number of gastric cancers developing after gastrectomy for duodenal, gastric, and combined gastric and duodenal ulcers were analysed by the $\chi^{2}$ test with Yates' correction.

Table 1 Calculation of expected deaths from gastric cancer in 267 male patients from 1971-1980

\begin{tabular}{lcll}
\hline & $\begin{array}{l}\text { England and } \\
\text { Wales death } \\
\text { rates from } \\
\text { CA stomach, } \\
\text { per } 10^{\circ}\end{array}$ & $\begin{array}{l}\text { Expected } \\
\text { deaths }\end{array}$ \\
$\begin{array}{l}\text { Age } \\
\text { group }\end{array}$ & $\begin{array}{l}\text { Person years } \\
\text { at risk }\end{array}$ & $50 \cdot 1$ & $0 \cdot 0002$ \\
\hline $40-44$ & 4 & $112 \cdot 5$ & $0 \cdot 0038$ \\
$45-49$ & $33 \cdot 5$ & $227 \cdot 7$ & $0 \cdot 0223$ \\
$50-54$ & 98 & $423 \cdot 0$ & $0 \cdot 0778$ \\
$55-59$ & 184 & $744 \cdot 1$ & $0 \cdot 2485$ \\
$60-64$ & 334 & $1248 \cdot 0$ & $0 \cdot 5778$ \\
$65-69$ & 463 & $1776 \cdot 7$ & $0 \cdot 7213$ \\
$70-74$ & 406 & $2246 \cdot 2$ & $0 \cdot 5683$ \\
$75-79$ & 253 & $2667 \cdot 0$ & $0 \cdot 2654$ \\
$80-84$ & $99 \cdot 5$ & $2672 \cdot 6$ & $0 \cdot 1791$ \\
$85+$ & 67 & & $2 \cdot 6645$ \\
\hline
\end{tabular}

\section{Results}

Of all the patients operated on between 1941 and 1949, 18 (17 men, one woman) have developed carcinomas of the gastric remnant which have been confirmed either at laparotomy or necropsy. Nine of the 18 carcinomas were diagnosed during the 10 year study period from 1971-80.

The mean age at the time of operation for peptic ulcer in these patients was 40 years (range 31-58 years) with a mean age at the diagnosis of gastric carcinoma of 65.5 years (range 60-79 years). Thirteen of the 18 carcinomas were diagnosed in the third postoperative decade. None was recognised before 15 years postgastrectomy (Figure). Eight of the patients who underwent gastric resection for duodenal ulceration $(1.6 \%)$ subsequently developed carcinoma of the stomach compared with seven patients who had resections for gastric ulceration $(7 \%)$. This difference is statistically significant $(\mathrm{p}<0.001)$. Three of the patients with combined gastric and duodenal ulcer disease who required gastrectomy also developed a carcinoma.

The expected number of deaths from carcinoma of the stomach in the 307 patients followed up during the period $1971-80$ was 2.66 for men and $0 \cdot 16$ for women. Because the mortality rates are for deaths certified as from carcinoma of the stomach only such deaths are included in the observed total. There were nine observed deaths (eight men, one woman) during this period. The chance of a 10 year

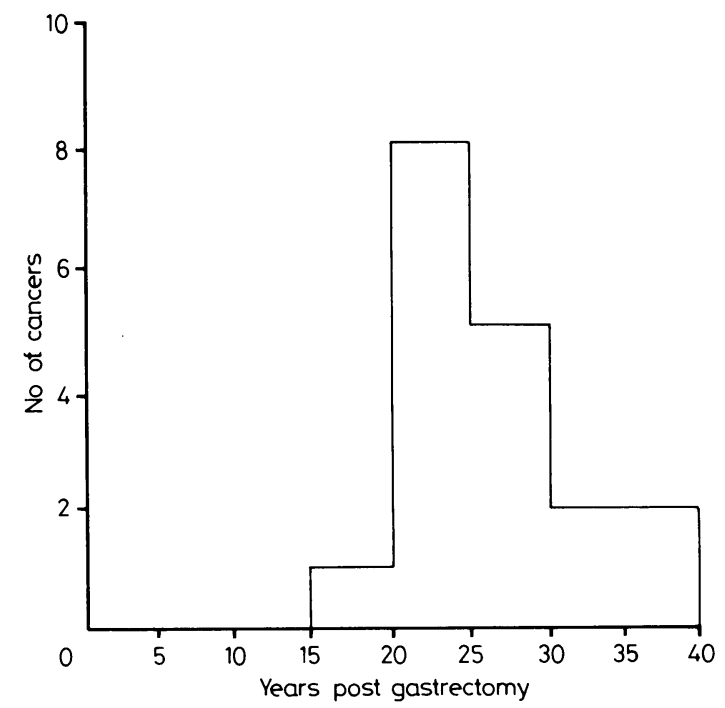

Figure Graph of number of cancers diagnosed in each five year period against number of years postgastrectomy. 
period containing eight or more male deaths from carcinoma of the stomach is less than one per cent.

Histological classification of the gastric remnant carcinomas revealed that in eight of the patients the tumour was intestinal in type and in one diffuse.

Endoscopic examination and biopsy of the gastric remnant was undertaken in 54 patients who were 31 to 39 years postgastrectomy. Many patients refused endoscopy, some lived too far away, and others were too aged and infirm. Bile reflux was invariably present at endoscopy. No carcinomas were detected in any of the patients endoscoped. Atrophic gastritis was present in 53 of the 54 patients biopsied and in 10 patients this was severe. Intestinal metaplasia was found in 24 patients and epithelial dysplasia of a mild or moderate degree was present in 19 patients. The severity of histological abnormality was not influenced by the site of the biopsy - that is, whether anterior or posterior to the stoma. Only one patient had normal gastric mucosa (Table 2).

\section{Discussion}

We have found that there is an increased risk of gastric carcinoma after partial gastrectomy for peptic ulcer although it must be accepted that the method used to calculate the risk is not ideal. The ratio of observed to expected deaths in this study was $3: 1$. When Helsingen and Hillestad ${ }^{1}$ compared the observed and expected mortality from carcinoma of the stomach in similar patients in Oslo they too found the ratio to be $3: 1$. Although it is possible that we did not diagnose all the gastric cancers which occurred in our study group, additions only add support to the conclusion of an increased incidence.

Out of a total of 18 carcinomas, 13 were

Table 2 Histological findings from endoscopic biopsy of the gastric remnant in 54 patients $31-39$ years

postgastrectomy

\begin{tabular}{lcc}
\hline Histology & $\begin{array}{l}\text { Patients } \\
(\text { no })\end{array}$ & $\%$ \\
\hline Normal & 1 & 2 \\
Atrophic gastritis & 13 & 24 \\
$\quad$ Mild & 30 & 55 \\
$\quad$ Moderate & 10 & 19 \\
$\quad$ Severe & 15 & 28 \\
Intestinal metaplasia & 4 & 7 \\
$\quad$ Mild & 5 & 9 \\
$\quad$ Moderate & & \\
$\quad$ Severe & 13 & 24 \\
Dysplasia & 6 & 11 \\
$\quad$ Mild & 0 & 0 \\
$\quad$ Moderate & 0 & \\
$\quad$ Severe & & \\
\hline
\end{tabular}

diagnosed in the third postoperative decade (Figure) which is consistent with the results of other studies $^{34} 610^{13}$ as is the finding that all but one of the carcinomas occurred in men. ${ }^{59}$ We have found that gastric resection for gastric ulcer resulted in a significantly greater risk of stomach cancer than resection for duodenal ulcer and this was also the conclusion of Helsingen and Hillestad ${ }^{1}$ and Giacosa et al. ${ }^{12}$ Others, however, have found no difference in the incidence of cancer in the gastric remnant after gastrectomy for duodenal or gastric ulcers. ${ }^{9}{ }^{10} \mathrm{We}$ note that patients who underwent gastrectomy for duodenal ulcer (a condition with a low risk of associated gastric cancer) develop carcinomas in the 'gastric stump' at a similar time postoperatively to patients who had resections for gastric ulcer.

There was no evidence of malignancy in any of the 54 patients we endoscoped. Only one patient, however, had normal gastric mucosa. Atrophic gastritis was present in all but one of our patients, and intestinal metaplasia of varying degrees of severity in almost half. Dysplasia was present in one third of the patients but in no case was it severe.

Several endoscopic studies of the gastric remnant have been carried out recently to attempt earlier diagnosis of 'gastric stump' cancer. Even though the mucosa rarely showed the macroscopic features of malignancy when viewed through the endoscope, a significant number of carcinomas were detected by taking multiple biopsies from around the gastroenterostomy. ${ }^{9} 1013$ In addition atrophic gastritis, intestinal metaplasia, and dysplasia have frequently been diagnosed. The findings from these studies are summarised in Table 3.

Long term follow up has shown an increased incidence of gastric carcinoma in patients with atrophic gastritis when compared with controls. ${ }^{17}$ It is widely accepted that intestinal metaplasia is a premalignant condition but Jass' work ${ }^{18}$ indicates that not all intestinal metaplasia possesses a malignant potential, but that there is an incomplete variant of the process which appears to be strongly associated with gastric cancer.

The management of the patient with severe dysplasia is not clear. ${ }^{10}{ }^{11}{ }^{19}$ While there is evidence that it can progress to frank carcinoma,${ }^{13}$ and some authorities would consider it an indication for resection of the remaining stomach,,$^{10}$ the assumption that it is a progressive change leading to cancer has not yet been borne out by long term studies.

Why did we not find any evidence of malignancy or severe dysplasia in the patients we endoscoped? It is possible that we have examined too few patients. Also Schrumpf and colleagues ${ }^{10}$ took 20 biopsies from around the stoma, and found that in patients in whom malignancy was detected only $12 \%$ 
Table 3 Comparison of histological findings reported in five endoscopic studies of the gastric remnant

\begin{tabular}{|c|c|c|c|c|c|c|c|}
\hline & $\begin{array}{l}\text { Patients } \\
\text { (no) }\end{array}$ & $\begin{array}{l}\text { Biopsies } \\
\text { (no) }\end{array}$ & Carcinoma & $\begin{array}{l}\text { Severe } \\
\text { dysplasia }\end{array}$ & Dysplasia & $\begin{array}{l}\text { Intestinal } \\
\text { metaplasia }\end{array}$ & $\begin{array}{l}\text { Atrophic } \\
\text { gastritis }\end{array}$ \\
\hline Schrumpf et al (Oslo) ${ }^{111}$ & 108 & 20 & $3 \%$ & $3 \%$ & $60 \%$ & $22 \%$ & $10 \%$ \\
\hline Domellöf et al (Umea) ${ }^{y}$ & 214 & 12 & $2 \%$ & $?$ & $?$ & $33 \%$ & $97 \%$ \\
\hline Huibregtse (Amsterdam) ${ }^{13}$ & 535 & 3 & $2 \%$ & $1.5 \%$ & $12 \%$ & $48 \%$ & $?$ \\
\hline Savage and Jones (Bristol) ${ }^{11} *$ & 63 & $8-10$ & 0 & $0+$ & $53 \%$ & $34 \%$ & $100 \%$ \\
\hline (York) & 54 & $6-8$ & 0 & 0 & $35 \%$ & $44 \%$ & $98 \%$ \\
\hline
\end{tabular}

* BI and BII gastrectomies.

+ One patient at follow up endoscopy was found to have severe dysplasia.

of the biopsies were positive for carcinoma; we took only six to eight biopsies and may therefore have missed some carcinomas. None have come to light so far, however. It is also conceivable that there is a peak incidence of gastric remnant carcinoma which occurs in the third postoperative decade. Our patients were not endoscoped until 31-39 years after operation.

Is the gastric cancer that occurs in the gastric remnant the same type of cancer that develops in the intact stomach? There is evidence that there are two types of gastric carcinoma,${ }^{20}$ one arising in normal mucosa (undifferentiated or diffuse) and the other in areas of abnormal mucosa particularly intestinal metaplasia (differentiated or intestinal). It might be expected, therefore, that in view of the high incidence of mucosal abnormalities found in the gastric remnant that the differentiated or intestinal type of carcinoma would predominate. This was the case in our study, the tumour being intestinal in type in eight of the nine gastric remnants examined. When Taksdal and Stalsberg compared the type of gastric cancer occurring in the gastric remnant and in the intact stomach, they found that the incidence of the intestinal type was almost the same in the two groups. $^{21}$

Endoscopic studies from Norway, ${ }^{10}$ Sweden, ${ }^{9}$ and Holland $^{13}$ have shown carcinomas in the gastric remnant many years after gastrectomy. The authors have, therefore, suggested routine endoscopic follow up of all postgastrectomy patients $15-20$ years after operation but difficulties lie in the path of its adoption. One of the main problems is to convince asymptomatic patients of the need to undergo endoscopy.

Severe dysplasia and mucosal carcinoma present difficulties in endoscopic diagnosis. The sampling error of 'blind' endoscopic biopsy at the stoma is considerable even when as many as 20 biopsies are taken $^{10}$ and the multiple specimens have then to be dealt with by the routine pathology services.

From our study the yield of severe dysplasia and carcinoma has not been fruitful. Although we have shown an increased risk of gastric carcinoma in postgastrectomy patients, we have not found any benefit to arise from endoscopic review and in this respect we differ from all overseas reports. We would suggest, however, that any postgastrectomy patient with abdominal symptoms more than 15 years after operation requires endoscopy with multiple biopsies taken from around the stoma.

Our thanks are due to Mr J Miller of the Yorkshire Cancer Registry for help in the analysis of the stomach cancer incidence data. Without Dr C N Pulvertaft's continuing supervision between $\mathrm{Mr}$ Visick's death in 1949 and the start of our survey in 1971, the York Gastric Clinic would not have continued to exist. Mrs R Nicolson, Mrs M Dent, Mrs S Dickson, and Mrs M Bill have provided invaluable help with maintaining contact with our patients and their records, and with the gastroscopy examination. We would also like to thank the York Peptic Ulcer Trust for providing financial support for secretarial assistance.

\section{References}

1 Helsingen $\mathrm{N}$, Hillestad L. Cancer development in the gastric stump after partial gastrectomy for ulcer. Ann Surg 1956; 143: 173-9.

2 Kobayashi S, Prolla JC, Kirsner JB. Late gastric carcinoma developing after surgery for benign conditions. Dig Dis 1970; 15: 905-12.

3 Stalsberg H, Taksdal S. Stomach cancer following gastric surgery for benign conditions. Lancet 1971; 2: 1175-7.

4 Terjesen T, Erichsen HG. Carcinoma of the gastric stump after operation for benign gastro-duodenal ulcer. Acta Chir Scand 1976; 142: 256-60.

5 Eberlein TJ, Lorenzo FV, Webster MW. Gastric carcinoma following operation for peptic ulcer disease. Ann Surg 1978; 187: 251-6.

6 Bushkin FL. Gastric remnant carcinoma. In: Bushkin FL, Woodward ER, eds. Postgastrectomy syndromes. 
Major problems in clinical surgery. Vol 10. London and Philadelphia, W B Saunders, 1976: 106-13.

7 Domellof L, Eriksson S, Janunger K-G. Late precancerous changes and carcinoma of the gastric stump after Billroth I resection. Am J Surg 1976; 132: 26-31.

8 De Boer J, Huibregtse K, Tytgat GN. Gastric carcinoma after partial gastrectomy. Tijdschr Gastroenterol 1978; 3: 157-66.

9 Domellof L, Eriksson S, Janunger K-G. Carcinoma and possible precancerous changes of the gastric stump after Billroth II resection. Gastroenterology 1977; 73: 462-8.

10 Schrumpf E, Serck-Hanssen A, Stadaas J. Mucosal changes in the gastric stump 20-25 years after partial gastrectomy. Lancet 1977; 2: 467-9.

11 Savage A, Jones S. Histological appearances of the gastric mucosa 15-27 years after partial gastrectomy. $J$ Clin Pathol 1979; 32: 179-86.

12 Giacosa A, Molinare F, Perasso A, Cheli R. Endoscopic experience in the diagnosis of gastric stump cancer. Front Gastrointest Res 1979; 5: 160-3.

13 Huibregtse $\mathrm{K}$. Endoscopic screening for malignancy in the gastric remnant. In: Cotton $\mathrm{P}$, ed. 2nd $B S G / S K \& F$ Workshop on early gastric cancer. London: British Society of Gastroenterology, 1981.
14 Visick AH. Measured radical gastrectomy. Review of 505 operations for peptic ulcer. Lancet 1948; 1: 505-10.

15 Whitehead R, Truelove SC, Gear MWL. The histological diagnosis of chronic gastritis in fibre optic gastroscope biopsy specimens. J Clin Pathol 1972; 25: $1-11$.

16 Lauren $\mathrm{P}$. The two histological main types of gastric carcinoma: diffuse and so-called intestinal type carcinoma. An attempt at a histo-clinical classification. Acta Pathol Microbiol Scand 1965; 64: 31-49.

17 Siurala M, Lehtola J, Ihamaki T. Atrophic gastritis and its sequelae. Scand J Gastroenterol 1974; 9: 441-6.

18 Jass JR, Filipe MI. A variant of intestinal metaplasia associated with gastric carcinoma: a histo-chemical study. Histopathology 1979; 3: 191-9.

19 Stokkeland M, Schrumpf E, Serck-Hanssen A et al. Incidence of malignancies of the Billroth II operated stomach. Scand J Gastroenterol 1981; suppl 67: 16: 169-71.

20 Nagayo T. Microscopical cancer of the stomach. A study on histogenesis of gastric carcinoma. Int J Cancer 1975; 16: 52-60.

21 Taksdal S, Stalsberg H. Histology of gastric cancer occurring after gastric surgery for benign conditions. Cancer 1973; 32: 162-6. 